Veronica de Lima Mittmann

Claudia Glavam Duarte

\title{
Coletivos, bandos, matilhas: devires de uma pesquisa sobre um curso de Licenciatura em Educação do Campo
}

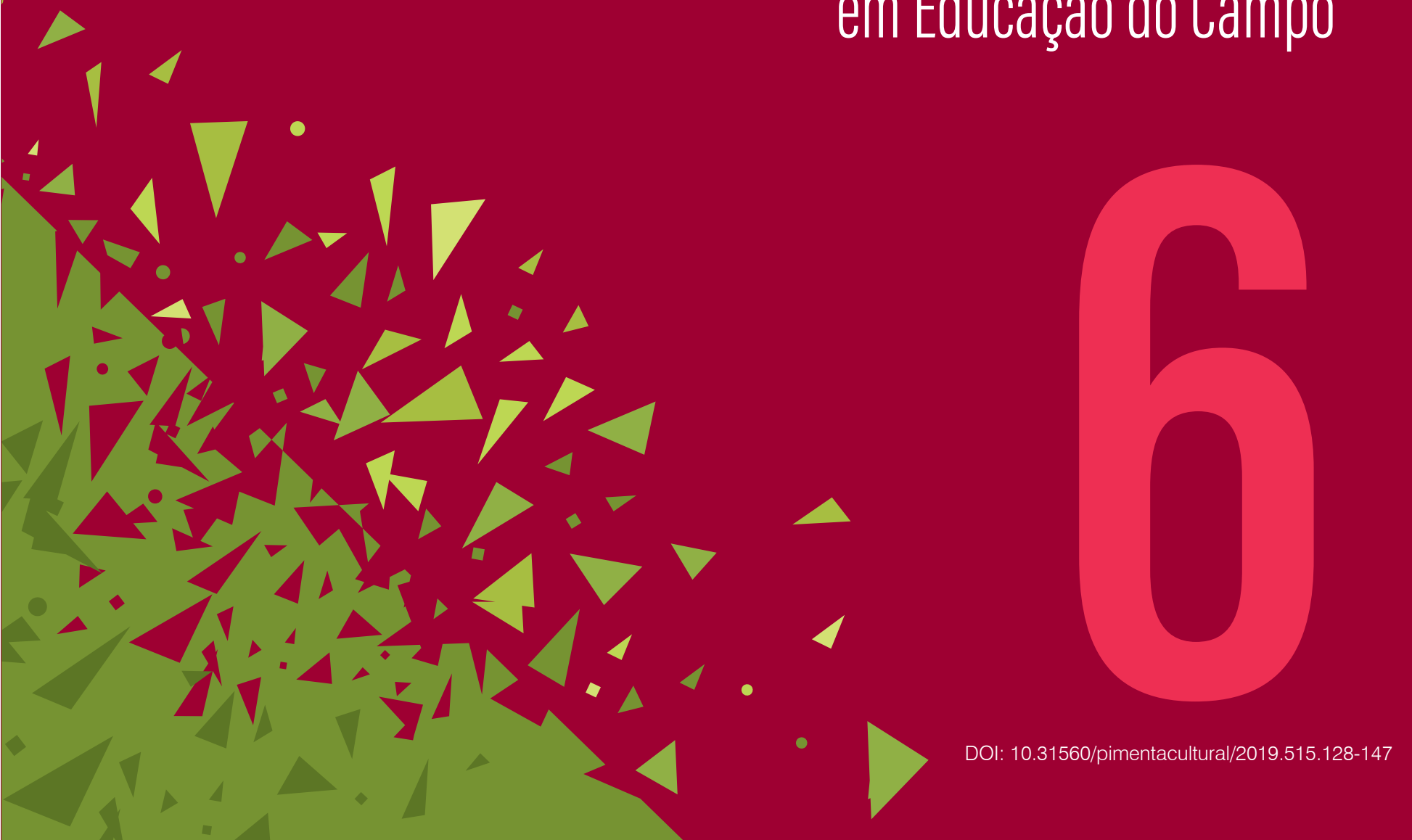


Uivar introduções...

\begin{abstract}
A suprema disciplina, que me impus, consistiu exatamente em negar-me a mim mesmo toda obstinação. Eu, macaco livre, aceitei esse jugo; mas, por isso mesmo, as recordações foram-se apagando em mim cada vez mais. Se bem que, se os homens o tivessem querido, eu teria podido retornar livremente, no começo, pela porta total que o céu forma sobre a terra, esta foi estreitando-se cada vez mais, à medida que minha evolução se ativava a poder de chicotadas: mais recluso, e melhor me sentia no mundo dos homens: a tempestade, que vinha do meu passado, soprava atrás de mim, foi-se acalmando: hoje, é apenas uma corrente de ar que me refresca os calcanhares. (KAFKA, 1977, p. 144).
\end{abstract}

Iniciamos o artigo com a epígrafe por entendermos que faz referência ao nosso processo de humanização, que teria se dado pelo esquecimento de nossa "animalidade", ou ainda, de uma humanização que se deu pela obediência às normas que, inventadas, esqueceram-se de que os são. Assim, este texto propõe-se a pensar em devires, ou seja, aquilo que ainda não somos, mas que temos potência para sermos. É neste exercício de sermos o que ainda não somos que escrevemos estas linhas. Acreditamos que escrever possibilita encontros com o desconhecido e destes encontros surgem devires que oportunizam ser diferente, pois, "se o escritor é um feiticeiro é porque escrever é um devir, escrever é atravessado por estranhos devires que não são devires escritor, mas devires-rato, devires-inseto, devires-lobo". (DELEUZE; GUATTARI, 2012, p. 20).

E por falar em encontros, ressaltamos que somos integrantes do Geemco (Grupo de Estudos em Educação Matemática e Contemporaneidade), ou seja, um bando constituído por diferentes membros, que tem o intuito de colocar como centro de nosso pensar a educação na contemporaneidade, especificamente a educação matemática, mas que não deixa, também, de abrigar investigações em diferentes áreas da educação, como por exemplo as Ciências 
da Natureza. Assim, também é crédito do grupo os pensamentos que circulam neste ensaio, pois são desfechos de problematizações produzidas nos encontros, afinal "como cada um de nós era vários, já era muita gente” (DELEUZE; GUATTARI, 1995, p.17).

Consideramos que escrever viabiliza transformar-se pelas linhas que se cria, ou como diria Mia Couto "dentro de mim, vão nascendo palavras líquidas num idioma que desconheço e me vai inundando todo inteiro. " (COUTO, 2009, p. 98), deixamo-nos inundar pelas multiplicidades destas páginas e pelos seus devires. Neste sentido, não acreditamos em uma "essência" animal guardada em nossa humanidade que pudesse ser resgatada, mas na potência do devir-animal no humano e do devir-humano no animal, sem que o homem se transforme em animal e o animal em humano.

Feitas as considerações iniciais, intencionamos com este ensaio ${ }^{1}$ problematizar a expressão "coletividade", utilizada recorrentemente por autores que são referências nos cursos de Licenciatura em Educação do Campo, ao justificarem a necessidade de um currículo por área de conhecimento na perspectiva da interdisciplinaridade. Nosso objetivo foi o de pensar os agrupamentos humanos à luz da Pedagogia da Diferença e, assim, dar outros contornos aos conceitos de bando (DELEUZE; GUATTARI) e de povo (FOUCAULT), para pensarmos talvez, em povo-matilha, povobando, povo-enxame. Cabe ressaltar ainda que escolhemos Kafka para compor nossa escrita, pela visceralidade de suas produções, muitas vezes inconclusas e surpreendentes. Assim, fomos arrastadas

1. Para Larrosa (2003), o ensaio seria uma forma menor de escrita, ou seja, uma forma derrotada, hibrida e impura. Uma escrita que enamorar a vida, que é trama de sensações, que é orgânica e se desfaz ao tempo, ou seja, não tem pretensão de eternidade. $\mathrm{O}$ ensaio borra a fronteira entre filosofia e literatura; entre ciência, conhecimento, racionalidade e arte, imaginação e irracionalidade. Assim, o ensaísta seria aquele que sente as palavras, que se surpreende com as leituras e que escreve com as vísceras, com o corpo, com medos e alegrias, com riso e lágrima. Além disso, o ensaísta ensaia a leitura cada vez que lê e ensaia a escrita quando escreve, isto é, se inventa pelos textos que produz e se compõe com os textos que lê. 
para os porões de nossa humanidade, para sentir a animalidade que espreita, que rosna, que salta, que arranha, que morde, e que nos atravessa e nos faz mais sensíveis, talvez.

\section{Metamorfosear o olhar...}

Certa manhã, ao despertar de sonhos intranquilos, Gregor Samsa encontrou-se em sua cama metamorfoseado num inseto monstruoso. Estava deitado sobre suas costas duras como couraça, e, quando levantou um pouco a cabeça, viu seu ventre abaulado, marrom, dividido em segmentos arqueados, sobre o qual a coberta, prestes a deslizar de vez, apenas se mantinha com dificuldade. Suas muitas pernas, lamentavelmente finas em comparação com o volume do resto de seu corpo, vibravam desamparadas ante seus olhos. (KAFKA, 2008, p. 13)

Quebrar as lentes! Criar fissuras na forma como olhamos o mundo e, assim, deixar-se arrebatar por outros sentires ou pelas linhas de fuga que nos atravessam para, quem sabe, devir-bicho, devir-inseto, devir-monstro. Neste sentido, com a intenção de metamorfosear o olhar, para possibilitar formas estrangeiras de enxergar o mundo e as coisas conhecidas, utilizamos algumas ferramentas foucaultianas como os conceitos de discurso, enunciado e verdade para operar com as enunciações que analisamos. Cabe destacar que discurso nesta perspectiva é compreendido não apenas como produto das subjetividades humanas, mas também como produtor de formas de vida, assim:

Dado que cada um de nós nasce num mundo que já é de linguagem, num mundo em que os discursos já estão há muito tempo circulando, nós nos tornamos sujeitos derivados desses discursos. Para Foucault, o sujeito de um discurso não é a origem individual e autônoma de um ato que traz à luz os enunciados desse discurso; ele não é o dono de uma intenção comunicativa, como se fosse capaz de se posicionar fora desse discurso para sobre ele falar. (VEIGANETO, 2014, p. 91). 
Já enunciado seria compreendido como aquilo que atravessa as falas e os escritos, mas que não seria nem as falas nem os escritos, ou seja, enunciado seria o que possibilita a existência de uma língua, haja visto, que "a língua só existe a título de sistema de construção para enunciados possíveis; mas, por outro lado, ela só existe a título de descrição (mais ou menos exaustiva) obtida a partir de um conjunto de enunciados reais. " (FOUCAULT, 2008, p. 96). Com isso, um enunciado seria raro, ou seja, é menos do que os atos de fala ou de escrita. Um enunciado também seria raro, pelo fato de ser em menor número do que a combinação possível de signos existentes, ou seja:

[...] poucas coisas, em suma, podem ser ditas, explicam que os enunciados não sejam, como o ar que respiramos, uma transparência infinita; mas sim coisas que se transmitem e se conservam, que têm um valor, e das quais procuramos nos apropriar; que repetimos, reproduzimos e transformamos. (FOUCAULT, 2008, p. 136).

Cabe também destacar que trabalhamos na exterioridade do dito, ou seja, nosso trabalho se assemelha ao do arqueólogo que procura no terreno diferentes objetos que contribuirão para contar uma história. Com isto, quando encontra os diferentes artefatos, não se interessa em abri-los para procurar o que há dentro deles, mas procura na superfície destes vestígios, pistas que ajudarão a entender um pouco a população que ali viveu. Assim, não procuramos interpretar o que nos foi dito, nem pensávamos que algo estivesse sendo-nos ocultado, mas trabalhamos na superfície dos enunciados, entendendo que "não há texto embaixo, portanto nenhuma pletora. O domínio enunciativo está, inteiro, em sua própria superfície. Cada enunciado ocupa aí um lugar que só a ele pertence. " (FOUCAULT, 2008, p. 135).

Um enunciado teria, ainda, algumas características que Ihes são próprias, como o grau de remanência, os fenômenos de recorrência e a forma de aditividade própria do enunciado. O grau 
de remanência de um enunciado tratar-se-ia dos suportes que um enunciado utiliza para sua conservação, ou seja, livros, bibliotecas. Com isso, "a remanência pertence, de pleno direito, ao enunciado; o esquecimento e a destruição são apenas, de certa forma, o grau zero da remanência.". (FOUCAULT, 2008, p. 140). Já os fenômenos de recorrência seriam o "campo de elementos antecedentes em relação aos quais se situa [um enunciado], mas que tem o poder de reorganizar e de redistribuir segundo relações novas" (FOUCAULT, 2008, p. 140), ou seja, a recorrência seria os enunciados que já estão em circulação e que sustentam a emergência de outros enunciados. Por último, um enunciado teria ainda uma forma de aditividade, que seria a maneira específica que diferentes discursos têm de "se compor, de se anular, de se excluir, de se completar, de formar grupos mais ou menos indissociáveis e dotados de propriedades singulares". (FOUCAULT, 2008, p. 140).

Além dos conceitos acima, que nos ajudaram a construir outros olhares para o material que emergiu, também entendemos a verdade como invenção, ou seja, "a verdade é deste mundo; ela é produzida nele graças a múltiplas coerções e nele produz efeitos regulamentados de poder". (FOUCAULT, 2016, p. 52). Com isto, não existiria uma verdade absoluta ou uma verdade a priori, ou seja, cada sociedade e cada época elegem os procedimentos necessários para a obtenção da verdade, e quais conhecimentos serão considerados verdadeiros. Neste sentido, poderíamos propor que, na atualidade, os conhecimentos pertencentes ao campo científico são compreendidos como "verdades contemporâneas".

\section{Farejar o local...}

Ao retroceder no tempo começo a lembrar-me de quando ainda era um membro da comunidade canina, partilhando suas preocupações, um cão entre cães e após um exame mais minucioso 
descubro que desde o início percebi alguma discrepância, alguns pequenos desajustamentos, causando uma ligeira sensação de mal-estar [...]. (KAFKA, 1998, p. 7)

Devir-cão para farejar o lugar, sentir seus odores e seus sons. Tornar-se aquilo que ainda não se é; experimentar sensações outras e intuições selvagens. Deixar-se surpreender pelo inesperado e pela imprevisibilidade dos momentos e dos encontros. E assim, não como um cão doméstico, mas quem sabe, como uma alcateia, nos aventuramos por lugares que nos eram desconhecidos. E, como lobos nômades que não cobiçavam dominar espaços, mas criar alguns contornos transitórios, nos propomos a pesquisar o território do curso de Licenciatura em Educação do Campo da Universidade Federal do Rio Grande do Sul- Campus Litoral Norte.

Cabe destacar que os cursos de Licenciatura em Educação do Campo surgem a partir da publicação do Edital $n^{\circ} 2$, de 23 de abril de 2008, da SESU/SETEC/SECADI/MEC como parte integrante do Programa de Apoio à Formação Superior em Licenciatura em Educação do Campo - PROCAMPO. Neste edital foi realizada uma chamada pública para as Universidades Federais interessadas em oferecer tal curso, sendo o critério de seleção a avaliação dos PPCs (Projeto Pedagógico de Curso) apresentados pelas instituições proponentes. Estes deveriam contemplar duas especificidades: a Pedagogia da Alternância e a organização curricular por áreas de conhecimento. Além disso, era especificada a necessidade de conhecer a realidade da comunidade que seria contemplada com o curso. Neste edital foram selecionadas 04 Universidades. Posterior a este, foram publicados o Edital $n^{\circ}$ 9, de 20 de abril de 2009 e o Edital $n^{\circ} 2$, de 05/09/2012 que contemplou 45 Universidades.

Assim, a Pedagogia da Alternância, a organização dos conteúdos por área de conhecimento e a interdisciplinaridade são especificidades deste curso. Isto posto, procuramos entender porque a 
interdisciplinaridade ${ }^{1}$ foi escolhida como perspectiva que estruturaria o currículo dos cursos de Licenciatura em Educação do Campo no Brasil e nos deparamos com a recorrência da expressão "coletividade" nas enunciações dos autores do referido curso (FERREIRA (2014); MOLINA (2014); LOPES (2014); BIZERRIL (2014); LOPES (2014). Deste modo, pareceu-nos que, para estes autores, a coletividade seria estruturante para a Educação do Campo e se constituiria em uma das condições de possibilidade para a construção de um currículo interdisciplinar, por área do conhecimento. Isto pode ser observado no trecho abaixo, quando Ferreira e Molina (2014) afirmam que o trabalho coletivo seria tão importante para a Educação do Campo que deveria acontecer já na construção dos projetos pedagógicos.

[...] o trabalho coletivo, conjunto, em parceria e comunhão entre docentes e entre docentes e educandos representa um espaço singular e profícuo para a materialidade do projeto político pedagógico escolar. (FERREIRA; MOLINA, 2014, p. 146).

Além disso, a formação por área de conhecimento possibilitaria também, repensar os Planos de Estudos e, deste modo, assegurar uma construção conjunta do currículo, que contemplasse o diálogo entre as diferentes áreas do conhecimento pelo "trabalho coletivo de educadores", conforme é possível perceber no trecho abaixo:

A formação por área de conhecimento objetiva contribuir com a transformação dos Planos de Estudos dos cursos, possibilitando novas estratégias de seleção de conteúdos, aproximando-os tanto quanto possível da realidade, bem como objetiva fomentar e promover o trabalho coletivo dos educadores [...] (MOLINA, 2014, p. 17).

Desta forma, percebemos que a construção coletiva de um Projeto Pedagógico e de um Plano de Estudos, seriam, para

1. A discussão sobre interdisciplinaridade pode ser consultada na dissertação de mestrado intitulada "Tudo é rede, conexão e simultaneidade! Problematizações foucaultianas sobre a interdisciplinaridade: um campo interdisciplinar de enunciabilidades disciplinares. Disponível em: https:// lume.ufrgs.br/bitstream/handle/10183/172124/001057096.pdf?sequence=1\&isAllowed=y 
os autores (FERREIRA (2014); MOLINA (2014); LOPES (2014); BIZERRIL (2014); LOPES (2014), a possibilidade de "pensar coletivamente" desde a construção do curso. Neste sentido, o trabalho coletivo, para estes autores, seria possibilitado tanto pelo diálogo entre os professores das diferentes áreas do conhecimento, na busca por metodologias que possibilitassem uma visão mais ampla da realidade, quanto por aproximações entre diferentes disciplinas, com a intenção de romper com as fronteiras do conhecimento, o que estabeleceria relações menos hegemônicas entre os diferentes componentes curriculares. Neste sentido, não se desprezaria a individualidade dos diferentes atores educacionais e nem as peculiaridades das diferentes áreas do conhecimento, pois acreditar-se-ia que um trabalho conjunto poderia se beneficiar dos diferentes "olhares", a fim de possibilitar a compreensão dos diferentes meandros da realidade, como é possível perceber nos trechos abaixo:

\footnotetext{
Um dos maiores desafios diz respeito à tensão enfrentada pelo coletivo de educadores que atuam nestas Licenciaturas para selecionar os conteúdos que devem ser ensinados, considerando-se não somente a perspectiva dos desafios inerentes à proposta formativa organizada a partir da interdisciplinaridade, [...]. (MOLINA, 2014, p. 18)

[...]a ser realizado no coletivo dos docentes, discentes e instituição como totalidade para que se estabeleça uma construção coletiva das finalidades, conhecimento/conteúdo tratados nos processos formativos dos Educadores do Campo. (FERREIRA; MOLINA, 2014, p. 139).

[...] o diálogo realizado entre as diferentes áreas do conhecimento caracteriza-se pela interdisciplinaridade que buscou superar a fragmentação do conhecimento acadêmico, as ações isoladas na formação dos estudantes, assim como na construção coletiva do currículo[...] (VASCONCELOS; SCALABRIN, 2014, p. 159).
}

\section{S U MÁRIO}

[...] os educadores, em planejamento coletivo, selecionam quais conhecimentos/conteúdos de sua área serão necessários para a compreensão do(s) tema(s) em estudo. (VASCONCELOS; SCALABRIN, 2014, p. 167).

[...] buscamos motivar os docentes que participaram do processo de formação realizado pelo Seminário das Áreas a registrar os passos que têm sido dados para enfrentar estes desafios, buscando, coletivamente, caminhos para sua superação. (MOLINA, 2014, p. 18). 
[...] os trabalhos se orientam pela formação continuada e o planejamento coletivo, possibilitando implementar o currículo interdisciplinar via tema gerador, [...] (VASCONCELOS, SCALABRIN, 2014, p. 176).

[...] considerar a interdisciplinaridade por meio de comunicação e planejamento coletivo por profissionais ligados às ciências da natureza[...]. (MORENO, 2014, p. 194).

[...] o trabalho coletivo e integrado de educadores dedicados propiciaram concretamente caminhos para o trabalho interdisciplinar. (LOPES; BIZERRIL, 2014, p. 226).

Também é importante salientar que a busca por relações menos hegemônicas não se daria apenas na escolha das disciplinas e entre os professores dos diferentes componentes curriculares, mas entre todos os envolvidos na construção do curso, que não seriam apenas os professores e a equipe pedagógica, mas também a comunidade. Assim, o "trabalho coletivo" deveria primar pela participação de todos, de maneira que se acredita igualitária, em prol do que se percebe como um bem comum. Com isto, os autores entendem que "o coletivo" possibilitaria a construção de relações mais justas e mais "humanas". E o reflexo deste "pensar" coletivo ocorreria na sala de aula, onde os alunos teriam "voz ativa" em seu processo de aprendizagem, e assim, se estabeleceriam relações menos hierarquizadas entre professores e alunos.

[... na Educação do Campo é o trabalho coletivo e integrado que rege muitas das relações em sala de aula. (LOPES; BIZERRIL, 2014, p. 206).

Os autores ainda acreditam que um currículo interdisciplinar, por área de conhecimento, favoreceria a formação de sujeitos conscientes e críticos, pois conhecendo a realidade em sua "totalidade", poderiam perceber como se engendram os processos sociais, e assim, estariam aptos a lutar "coletivamente" por mudanças, na busca por uma sociedade mais justa. Neste sentido, o "pensar coletivo" poderia ser potencializado por um currículo interdisciplinar e este ser ferramenta de luta por melhores condições de vida para os sujeitos do campo. 
Por isso [a interdisciplinaridade] ela é tão essencial aos processos que visam à leitura da realidade e sua transformação, pois o especialista, com a sua visão restrita, muitas vezes não carrega consigo a disponibilidade de abrir-se para novas possibilidades que surgem a partir de pensar coletivo e integrado. (LOPES; BIZERRIL, 2014, p. 207).

[...] o currículo é uma prática social exercida pelos sujeitos em um coletivo de trabalho e de estudo, ou como nos antecipa Freire (2004), prática social exercida pelos sujeitos em comunhão mediatizados pelo mundo. (FERREIRA; MOLINA, 2014, p. 139).

Conforme o exposto acima, percebemos que o "coletivo" é recorrente nas enunciações e não se limitaria a um "trabalho coletivo", mas também se almejaria um "pensar coletivo" viabilizado por um "planejamento coletivo". À vista disso, nos propomos a problematizar a recorrência do enunciado que trata da importância da coletividade para os sujeitos do campo, nas enunciações dos autores da Licenciatura em Educação do Campo, e para tal problematização, nos aventuramos nos conceitos de: povo (FOUCAULT, 2008) e de manada, bando, enxame, cardume (DELEUZE; GUATTARI, 2000) para pensar em devires-animais no curso de Licenciatura em Educação do Campo.

S U MÁRIO

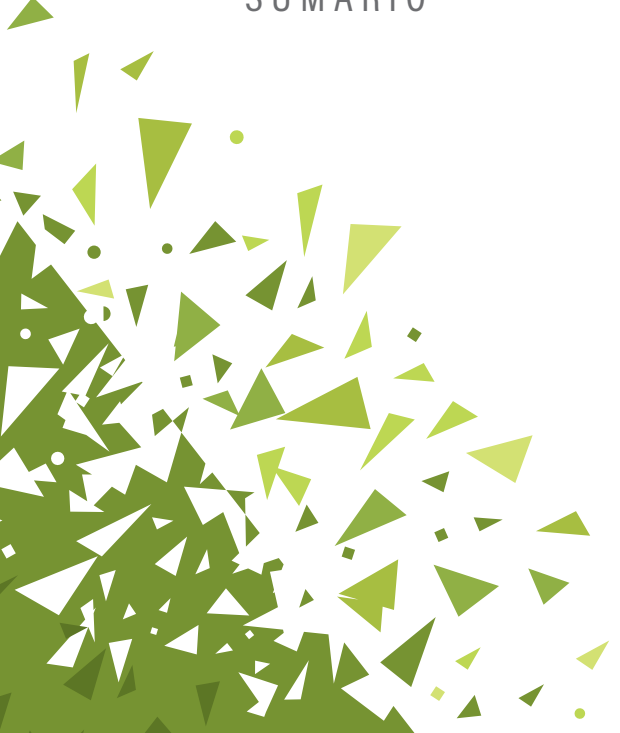

\section{Mordiscar sentidos...}

\begin{abstract}
- Ah! - Disse o camundongo-, o mundo se torna mais estreito a cada dia. Primeiro ele era tão vasto que eu tinha medo, andava um pouco e me alegrava por finalmente ver à distância paredes à direita e à esquerda, mas essas longas paredes correm tão rapidamente uma em direção à outra que já estou no último aposento, e ali no canto está a armadilha para a qual me dirijo. (KAFKA, 2010, p.92).
\end{abstract}

Afastar um pouco as paredes para tornar o mundo um pouco mais vasto e expandir os sentires. Neste sentido, entendemos que o devir-animal seria a possibilidade de sentir de outros modos, pela ação de deixar-se povoar por outros paladares, por outros tatos e odores, para experimentar sensações outras, e se surpreender 
com a vida. O devir seria o exercício que possibilita ouvir de outros modos e falar outras línguas, que ainda não foram nem mesmo criadas; ou ainda "gaguejar a própria língua, fazendo funcionar novas possibilidades. " (GALLO; FIGUEIREDO, 2015, p. 36). Com isto, o devir seria movimentos de desterritorialização, que viabilizam atingir intensidades puras, onde aquilo que nos acontece ainda não pode ser significado; o que possibilita, talvez, uma invenção de si mesmo, por experiências outras de existir.

Os devires-animais não são sonhos nem fantasmas. Eles são perfeitamente reais. Mas de que realidade se trata? Pois se o devir animal não consiste em se fazer de animal ou imitá-lo, é evidente também que o homem não devém "realmente" animal, como tampouco o animal devém "realmente" outra coisa. O devir não produz outra coisa senão ele próprio. É uma falsa alternativa que nos faz dizer: ou imitamos, ou somos. O que é real é o próprio devir, o bloco devir, e não os termos supostamente fixos pelos quais passaria aquele que devém. O devir pode e deve ser qualificado como devir-animal sem ter um termo que seria o animal devindo. O devir-animal do homem é real, sem que seja real o animal que ele devém; e simultaneamente, o devir-outro do animal é real sem que esse outro seja real. (DELEUZE; GUATTARI, 2012, p. 19).

Assim, por ser um transformar-se animal ou uma metamorSU MÁR I 0 fose-animal, o devir-animal não deve ser confundido com metáforas, ou seja, o devir-animal não se trata de um sentido figurado da linguagem, nem de uma semelhança que haveria entre o homem e o animal, ou de um comportamento do animal que se parece com o comportamento do humano. Com isto, o devir-animal seria uma metamorfose, que desterritorializa tanto o animal quanto o homem, ou seja, o devir se trata de experimentações que não foram fixadas pelos significantes, pois:

O animal não fala "como" um homem, mas extrai da linguagem tonalidades sem significação; as palavras mesmas não são "como" animais, mas trepam por sua conta, latem, pululam, sendo cães propriamente linguísticos, insetos e camundongos. Fazer vibrar sequencias, abrir a palavra sobre intensidades interiores inauditas, em suma, um uso intensivo assignificante da língua. (DELEUZE; GUATTARI, 2014, p. 45). 
Nesta perspectiva, o devir seria minoritário, isto é, há devires-animal, devires-mulher, devires-criança, mas não haveria um devir-homem, haja vista ser o homem, branco, macho e europeu um estado de dominação, ou seja, o modelo instituído. Neste sentido, o devir seria aquilo que foge ao padrão e afirma a diferença e também a multiplicidade: matilha, bando, cardume, enxame, multidão, ou seja, uma "composição de velocidades e de afectos entre indivíduos inteiramente diferentes" (Ibidem, p. 46). Sendo o devir, multidão, o "devir lobo", não seria devir um único lobo, mas um devir "matilha". Assim, a multiplicidade residiria no próprio devir, pois seria este um povoamento da diferença. Neste sentido, entendemos que para os devires, seriam necessários múltiplos agenciamentos, pois:

\begin{abstract}
[...] um agenciamento põe em conexão certas multiplicidades tomadas em cada uma destas ordens, de tal maneira que um livro não tem sua continuação no livro seguinte, nem seu objeto no mundo nem seu sujeito em um ou em vários autores. Resumindo, parece-nos que a escrita nunca se fará suficientemente em nome de um fora. $O$ fora não tem imagem, nem significação, nem subjetividade. O livro, agenciamento com o fora contra o livro-imagem do mundo. (DELEUZE; GUATTARI, 1995, p. 33).
\end{abstract}

Com isto, devires menores ou minorias não se referem a S U M ÁRIO números, ou seja, não seriam minorias por haver menos membros, mas por serem aquilo que foge ao modelo ou que rompe com a norma. Assim, as minorias são o devir, a invenção, enquanto a maioria seria o instituído, isto é, o dominante. Com isto, por não ser o padrão, mas a fissura do modelo, a potência dos devires menores está na inventividade. Para pensar minorias, pensamos em devir-animal, que não seria um "imitar animal", mas um transformar-se, ou seja, tornar-se não um animal, ou um determinado animal, mas tornar-se também animal. Desta forma, o devir não seria o resultado, mas o movimento.

Devir-animal é precisamente fazer o movimento, traçar a linha de fuga em toda a positividade, ultrapassar um limiar, atingir um continuum de intensidades que só valem por si mesmas, encontrar um 
mundo de intensidades puras, em que todas as formas se desfazem, todas as significações também, significantes e significados, em proveito de uma matéria não formada, de fluxos desterritorializados, de signos assignificantes. (DELEUZE; GUATTARI, 2014, p. 27).

Pensar em devires menores nos instiga a pensar em línguas e em literaturas menores. Segundo Gallo e Figueiredo (2015) haveria uma "língua maior" e uma "língua menor". A língua maior seria a dos dominantes e por isso, entende como necessário a homogeneidade e a organização. Seria a língua maior, o modelo, que preza pela "pureza" e pela norma; enquanto a língua menor seria heterogênea, múltipla, diversa, ou seja, seria devir e multiplicidade. Segundo Deleuze e Guattari (2014) uma língua ou ainda, uma literatura menor teria como característica ser revolucionária em relação a uma língua ou a uma literatura maior, pois propõe a "desterritorialização da língua, a ligação do individual no imediato-político e o agenciamento coletivo de enunciação". (Ibidem, p. 39). Nesta mesma lógica, por entender que existem línguas maiores e línguas menores e que, em geral, as línguas que utilizamos são as línguas dos colonizadores e por isso, línguas maiores; Deleuze e Guattari nos propõem criar línguas menores na nossa própria língua, ou ainda desterritorializar a língua-maior de nosso idioma. Pois:

Quantas pessoas hoje vivem em uma língua que não é a sua? Ou então não conhecem mesmo mais a sua, ou não ainda, conhecem mal a língua maior de que são forçados a se servir? Problema dos imigrados, e sobretudo de seus filhos. Problema das minorias. Problema de uma literatura menor, mas também para nós todos: como arrancar de sua própria língua uma literatura menor, capaz de escavar a linguagem, e de fazê-la escoar seguindo uma linha revolucionária sóbria? Como devir o nômade e o imigrante e o cigano de sua própria língua? Kafka diz: roubar a criança no berço, dançar sobre a corda bamba. (DELEUZE; GUATTARI, 2014, p. 40-41).

Para isto, "[...] aspiramos regressar a essa condição em que estivemos tão fora de um idioma que todas as línguas eram nossas[...]" (COUTO, 2011, p. 8), a fim de estranhar hábitos, que nos aprisionam numa existência "já vivida" e que impossibilita 
experimentar outros devires, ou a vida de outros modos. Acreditamos que as coisas que aprendemos nos sãos úteis, pois possibilitam percorrer caminhos já traçados, mas, por ora, acreditamos ser instigante, desconhecer, para ter a ousadia de, quem sabe, se surpreender novamente com a vida.

Neste sentido, um dos contrapontos entre o conceito de "devir-animal" e o conceito de "coletividade" defendido pelos autores do curso de Licenciatura em Educação do Campo, se daria pela própria organização que propõe. Enquanto o coletivo entende como necessário a "massa", o "devir-animal" propõe agenciamentos e metamorfoses. Assim, entendemos ser importante diferenciar massa de matilha. Massa remeteria à "divisibilidade e à igualdade dos membros, à concentração, à sociabilidade do conjunto, à unicidade da direção hierárquica, à organização de territorialização, à emissão de signos." (DELEUZE; GUATTARI, 2000, p. 45). Com isto, "a essência das massas é a indiferença: todas as diferenças são submersas e afogadas nas massas". (HARDT; NEGRI, 2005, p. 12). Já a matilha remeteria à diferença, à multiplicidade de devires e agenciamentos. Neste sentido, a matilha seria composta por inúmeras diferenças que não poderiam ser contempladas por uma "identidade" como ocorre na massa. Assim, não haveria a intenção de se construir modelos ou homogeneidades na matilha, nem mesmo haveria relações hierárquicas entre os seus diferentes membros, mas experimentações e desterritorializações.

Entre os caracteres de matilha, a exigüidade ou a restrição do número, a dispersão, as distâncias variáveis indecomponíveis, as metamorfoses qualitativas, as desigualdades como restos ou ultrapassagens, a impossibilidade de uma totalização ou de uma hierarquização fixas, a variedade browniana das direções, as linhas de desterritorialização, a projeção de partículas. (DELEUZE; GUATTARI, 2000, p. 45).

Com isto, a coletividade estaria mais ligada ao conceito de massa do que ao conceito de matilha, pois pressupõe acordos coletivos, em prol de um bem comum, igualdade entre os membros, e 
até mesmo, a constituição de uma identidade. Outro conceito que poderia ser utilizado para pensar o coletivo, seria o de população que se contrapõe ao conceito de povo. Para Foucault (2008) haveria diferença entre povo e população, ou seja, povo seria aquele que ainda não foi normatizado, ou seja, é o selvagem enquanto a população seriam os sujeitos disciplinados, ou seja, que já se enquadraram às normas. Assim, população seria o sujeito coletivo, ou seja, que abdica de seus instintos e desejos, em nome do grupo. No entanto:

[...] o povo aparece como sendo, de uma maneira geral, aquele que resiste a regulação da população, que tenta escapar desse dispositivo pelo qual a população existe, se mantém, subsiste, e subsiste num nível ótimo. (FOUCAULT, 2008, p. 58).

Assim, poderíamos pensar num bando-povo (GALLO; FIGUEIREDO, 2015), para viabilizar a invenção de outros "modos de vida", ou talvez re-criar "pequenas" humanidades, que combinariam diferentes devires-menores. Deste modo, ao invés de disciplinar para o enquadramento, poderíamos tentar perceber potências no diferente, onde não haveria a dominação de um "modelo" de humano (homem, branco, macho, europeu), mas diferentes experimentações da humanidade/animalidade.

\title{
SU MÁRIO
}

\begin{abstract}
Não somente existem bandos humanos, como também, entre eles, alguns particularmente refinados: a "mundanidade" distingue-se da "socialidade" porque está mais próxima de uma matilha, e o homem social tem do mundano uma certa imagem invejosa e errônea, porque desconhece as posições e as hierarquias próprias, as relações de força, as ambições e os projetos bastante especiais. (DELEUZE; GUATTARI, 2000, p. 46).
\end{abstract}

Os conceitos de povo de Foucault e de devir-animal de Deleuze e Guattari nos instigam a pensar quais seriam os devires menores da Educação do Campo e assim, poder criar fissuras na Educação-maior, ou seja, nas formas de ensinar que dominam o ensino na atualidade e que impedem a criação de outras maneiras de aprender, que sejam mais instintivas e instigantes. Neste sentido, 
a Educação do Campo, por ser compreendida como uma "educação-menor", seria espaço de inventividade e produção do diferente. Com isto, acreditamos na potencialidade da Educação do Campo como promotora de experimentações e de vivências outras.

\title{
Digerir conceitos...
}

\begin{abstract}
Durante horas posso me esgueirar pelos meus corredores, sem ouvir outra coisa senão, algumas vezes, o zunido de algum bicho pequeno, que eu logo sossego entre os meus dentes, ou o escorrer da terra, que me aponta a necessidade de alguma reforma; de resto, tudo quieto. (KAFKA, 1998, p. 66).
\end{abstract}

Nestas linhas, procuramos por "uma só e mesma paixão por escrever, mas não a mesma”. (DELEUZE; GUATTARI, 2014, p. 76) para experimentar na pele a crueldade da vida, que não a define nem como má, nem como perversa, mas como indomável e instintiva. Assim, pensar em devires-animais, aguça-nos para sensações viscerais de uma escrita feita de olfatos, de dentes e de garras. E com isto, arrancados de nossas convicções, tivemos que farejar outras percepções para experimentar a vida de outros modos.

Ao ir finalizando este ensaio, entendemos que escrevemos estas linhas "só para falar de coisas miúdas, as grandezas do ínfimo” (BARROS, 2017, p. 7), do que nos é corriqueiro, do já tão acostumado que deixamos de pensar que poderiam ser diferentes. Com isto, pensar em devir-animal para a Educação do Campo pressupõe pensar em uma educação que expanda nossos sentires, que seja criativa e que ao invés de nos dividir em grupos ou classes, seja potente para transformações. Uma educação que nos possibilite composições diversas, para sermos um pouco mais povo, isto é, "necessita-se ao mesmo tempo de criação e povo". (DELEUZE, 1992, p. 218), ou seja, um ensino que não intencione homogeneizar, mas que contemple o que temos de "mundano". E talvez, um pouco 
menos domesticados, possamos trazer elementos outros para os nossos bandos e, com isto, arranhar certezas e verdades, para quem sabe, poder produzir outros uivos na sociedade atual.

\section{Referências}

BAUMAN, Zygmunt. A ética é possível em um mundo de consumidores? Rio de Janeiro: Zahar, 2008.

BARROS, Manoel de. O guardador de águas. Rio de Janeiro: Alfaguara, 2017. COUTO, Mia. O fio das missangas. São Paulo: Companhia das Letras, 2009.

COUTO, Mia. E se Obama fosse africano? e outras interinvenções. São Paulo: Companhia das Letras, 2011.

DELEUZE, Gilles; GUATTARI, Félix. Kafka: por uma literatura menor. Belo Horizonte: Autêntica Editora, 2014.

DELEUZE, Gilles; GUATTARI, Félix. Mil Platôs: capitalismo e esquizofrenia, v.1. Rio de Janeiro: Editora 34, 1995

DELEUZE, Gilles; GUATTARI, Félix. Mil Platôs: capitalismo e esquizofrenia, v.4. Rio de Janeiro: Editora 34, 2012.

DELEUZE, Gilles. Conversações. São Paulo: Editora 34, 1992.

S U MÁRIO

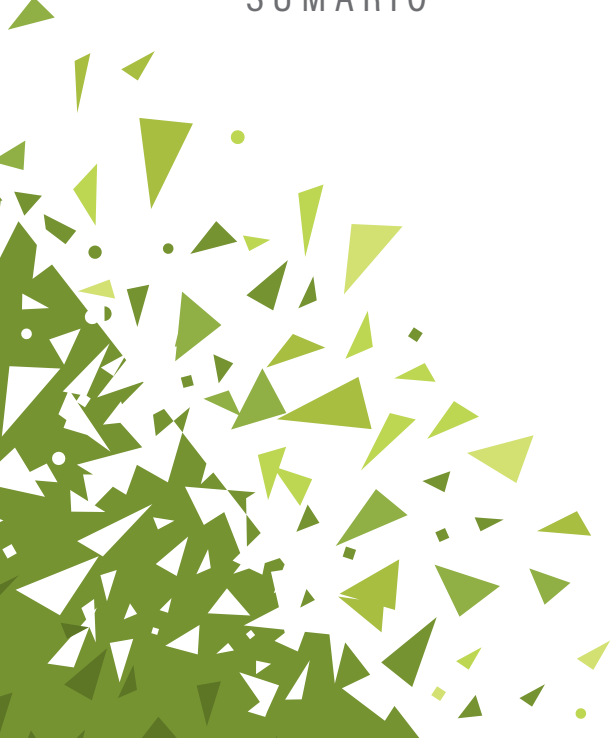

FERREIRA, Maria Jucilene Lima; MOLINA, Mônica Castagna. Desafios à formação de educadores do Campo: tecendo algumas relações entre os pensamentos de Pistrak e Paulo Freire. In: MOLINA, Mônica Castagna (Org.). Licenciaturas em Educação do Campo e o ensino de Ciências Naturais: desafios à promoção do trabalho docente interdisciplinar. Brasília: MDA, 2014. p. 127-154.

FONSECA, Márcio Alves. Michel Foucault e a constituição do sujeito. São Paulo: EDUC, 1995.

FOUCAULT, Michel. A arqueologia do saber. Rio de Janeiro: Forense Universitária, 2008.

FOUCAULT, Michel. Segurança, território, população: curso dado no Collège de France (1977-1978). São Paulo: Martins Fontes, 2008b.

FOUCAULT, Michel. Estratégia, poder-saber. Rio de Janeiro: Forense Universitária, 2006. (Ditos e Escritos IV). 
FOUCAULT, Michel. Microfísica do Poder. Rio de Janeiro: Paz e Terra, 2016.

FOUCAULT, Michel. A verdade e as formas jurídicas. Rio de Janeiro: Nau, 1999.

GALLO, S.; SILVA, Glaúcia Maria Figueiredo. Entre maioridade e menoridade: as regiões de fronteira no cotidiano escolar. Aprender Caderno de Filosofia e Psicologia da Educação, v. 14, p. 25-51, 2015.

HARDT, Michael. A sociedade mundial de controle. In: ALLIEZ, Éric. Gilles Deleuze: uma vida filosófica. São Paulo: Ed 34, 2000. P. 357-372.

HARDT, Michael; NEGRI, Antonio. Multidão: Guerra e Democracia na Era do Império. Rio de janeiro: Record, 2005.

KAFKA, Franz. Um Artista da fome e a Construção. São Paulo: Companhia das Letras, 1998.

KAFKA, Franz. A Grande Muralha da China. São Paulo: Nova Época Editorial Ltda, S/A.

KAFKA, Franz. Josefina, a Cantora. São Paulo: Clube do Livro, 1977.

KAFKA, Franz. A metamorfose e o Veredito. Porto Alegre: L\&PM, 2008.

KAFKA, Franz. Oportunidade para um pequeno desespero. São Paulo: Martins Martins Fontes, 2010.

LARROSA, Jorge. O ensaio e a escrita acadêmica. Revista Educação e Realidade, Porto Alegre, v. 28, n.2, p. 101-115, jul./dez. 2003.

LOPES, Eloisa Assunção de Melo; BIZERRIL, Marcelo Ximenes A. Video e Educação do Campo: novas tecnologias favorecendo o Ensino de Ciências Interdisciplinar. In: MOLINA, Mônica Castagna (Org.). Licenciaturas em Educação do Campo e o ensino de Ciências Naturais: desafios à promoção do trabalho docente interdisciplinar. Brasília: MDA, 2014, p. 200-229.

MORENO, Glaucia de Sousa. Ensino de Ciências da Natureza, Interdisciplinaridade e Educação do Campo. In: MOLINA, Mônica Castagna (Org.). Licenciaturas em Educação do Campo e o ensino de Ciências Naturais: desafios à promoção do trabalho docente interdisciplinar. Brasília: MDA, 2014. p. 181-200.

MOLINA, Mônica Castagna (Org.). Licenciaturas em Educação do Campo e o ensino de Ciências Naturais: desafios à promoção do trabalho docente interdisciplinar. Brasília: MDA, 2014. 268p

SARAIVA, Karla; VEIGA-NETO, Alfredo. Modernida Líquida, Capitalismo Cognitivo e Educação. Revista Educação e Realidade, Porto Alegre, v. 34, n. 2, p. 187-201, mai./ago. 2009. 
SERRES, Michel. Polegarzinha: uma nova forma de viver em harmonia, de pensar as instituições, de ser e de saber. Rio de Janeiro: Bertrand Brasil, 2013.

SILVA, Penha Souza; AUAREK, Wagner Ahmad. Pensando a formação continuada de Educadores do Campo: o diálogo no ensino da Ciências da Natureza e da Matemática nas Escolas do Campo. In: MOLINA, Mônica Castagna (Org.). Licenciaturas em Educação do Campo e o ensino de Ciências Naturais: desafios à promoção do trabalho docente interdisciplinar. Brasília: MDA, 2014, p. 231-241.

VASCONCELOS, Vanilda de Magalhães Martins; SCALABRIN, Rosemeri. Ensino interdisciplinar na área de Ciência da Natureza e Matemática em um contexto agroecológico. In: MOLINA, Mônica Castagna (Org.). Licenciaturas em Educação do Campo e o ensino de Ciências Naturais: desafios à promoção do trabalho docente interdisciplinar. Brasília: MDA, 2014, p. 154-179

VEIGA-NETO, Alfredo. Foucault e a educação. Belo Horizonte: Autêntica, 2014.

SU MÁRIO

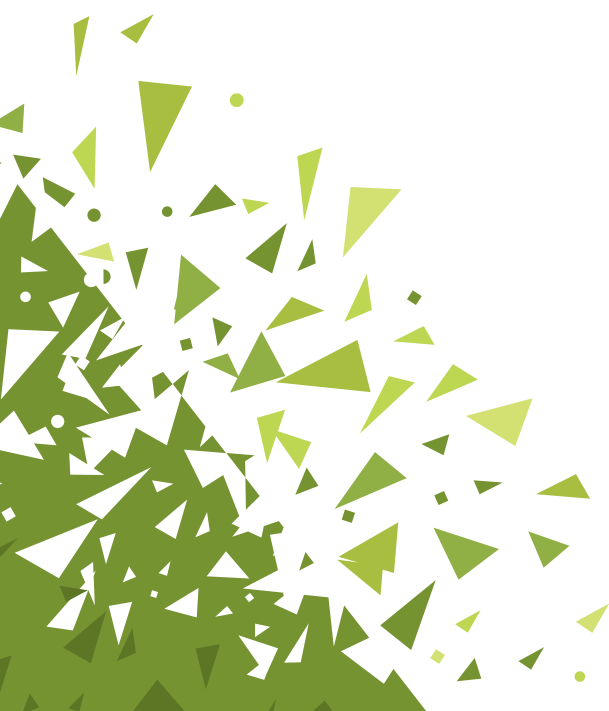

